\title{
VARIABILIDADE ESPACIAL DA TEXTURA DE UM LATOSSOLO SOB CULTIVO DE CITROS
}

\author{
Spatial variability of texture in an Oxisol cultivated with citrus
}

\author{
Marissol G. A. Leão ${ }^{1}$, José Marques Júnior² ${ }^{2}$ Zigomar Menezes de Souza ${ }^{3}$, Gener Tadeu Pereira $^{4}$
}

\begin{abstract}
RESUMO
O relevo influencia a variabilidade da textura, uma vez que condiciona o tempo de exposição dos materiais à ação do intemperismo. Neste trabalho, desenvolvido no município de Gavião Peixoto (SP), objetivou-se caracterizar a variabilidade espacial da textura de um Latossolo Vermelho distrófico sob cultivo de citros. A encosta foi dividida em três segmentos: topo, meia encosta e encosta inferior. O solo foi amostrado em malha, com intervalos regulares de $50 \mathrm{~m}$, perfazendo o total de 332 pontos em uma área de 83,5 ha, nas profundidades de 0,0-0,2 m e 0,6-0,8 m. Os dados foram submetidos à análise estatística descritiva e geoestatística (modelagem de semivariogramas e mapas de krigagem). O comportamento espacial da textura de latossolos está diretamente relacionado com as formas do relevo neste estudo, que controla o sentido dos fluxos de água superficial e subsuperficial. O conceito de homogeneidade da distribuição de argila no perfil dos latossolos é uma informação que pode ser ajustada pelo conhecimento do padrão espacial dessa distribuição em diferentes formas do relevo.
\end{abstract}

Termos para indexação: geoestatística, relação solo-paisagem, frações granulométricas.

\begin{abstract}
Relief influences soil texture variability, since it contributes to the time of exposition of the materials to weathering factors. Our work was carried out in the city of Gavião Peixoto (SP), with the objective of characterizing the spatial variability of texture of a dystrophic Red Latosol cultivated with citrus. The hillside was divided into three segments: top, stocking lean and inferior lean. Soil samples were collected in a grid with regular intervals of $50 \mathrm{~m}$, at the depths of 0.0-0.2 $\mathrm{m}$ and 0.6-0.8 m, comprising a total of 332 points in an area of 83.5 ha. The data were submitted to descriptive and geostatistics analyses (semivariogram modeling and kriging maps). The spatial behavior of the texture of oxisols is directly related to the relief forms in this study, which controls the direction of surface and subsurface water flows. The concept of homogeneity of clay distribution in the Oxisol profile is a piece of information that can be adjusted by knowing the spatial pattern of this distribution in different relief forms.
\end{abstract}

Index terms: geostatistics, soil-landscape relation, granulometric fractions.

(Recebido em 2 de outubro de 2007 e aprovado em 18 de agosto de 2009)

\section{INTRODUÇÃO}

A variabilidade da granulometria do solo está relacionada ao material de origem, e este pode depender do ambiente deposicional dos sedimentos, do tipo de rocha que originou o solo e de processos pedogenéticos (Daniels $\&$ Nelson, 1987). No caso da formação Adamantina, onde se localiza o local de estudo, está relacionado com sedimentos areníticos fluviais de granulação fina a muito fina (Ibrahim, 2002). Além do material de origem, o relevo influencia a variabilidade da textura, uma vez que condiciona o tempo de exposição dos materiais à ação do intemperismo.

Segundo Wysocki \& Schoeneberger (1999), a topografia e o material de origem atuam no controle local sobre o movimento de água, teor de nutrientes e temperatura do solo. Esses autores asseguram que nos últimos vinte anos, houve um grande avanço no conhecimento do solo como um sistema dinâmico, decorrente dos estudos do movimento de água superficial e subsuperficial, possibilitando o entendimento dos solos como agente integrador da paisagem. Nesse sentido, os processos que ocorrerem no topo da paisagem afetam os demais solos na vertente, em razão dos fluxos de energia e massa dos solos (forças que favorecem a pedogênese) que integram os processos de transporte e sedimentação (Wilding \& Drees, 1983).

O conhecimento da textura é importante para definir classes taxonômicas (Webster \& Butler, 1976), inferir os processos pedogenéticos atuantes (Young et al., 1999), e ainda auxiliar no entendimento do movimento de água no corpo do solo, no manejo da adubação, prever as necessidades de práticas conservacionistas, essenciais para o planejamento ambiental (Bouma et al., 1999). Por meio de um modelo de elevação digital, Gobin et al. (2001) avaliaram o comportamento de uma vertente, utilizando as

\footnotetext{
${ }^{1}$ Faculdade de Ciências Agrárias e Veterinárias UNESP - Via de Acesso Professor Paulo Donato Castellane, s/n - $14884-900$ - Jaboticabal, SP — marissol@fcav.unesp.br

${ }^{2}$ Faculdade de Ciências Agrárias e Veterinárias UNESP - Jaboticabal, SP - marques@fcav.unesp.br

${ }^{3}$ Faculdade de Engenharia Agrícola UNICAMP - Campinas, SP

${ }^{4}$ Faculdade de Ciências Agrárias e Veterinárias - Departamento de Ciências Exatas UNESP - Jaboticabal, SP
} 
relações entre atributos do solo e do relevo. Os autores relacionaram a distribuição da argila e silte aos índices topográficos e gradiente de declividade, e a distribuição da areia aos aspectos da hidrologia.

Portanto, para realizar o estudo da variabilidade de atributos do solo têm sido utilizadas diversas metodologias, tais como: a classificação numérica, estatística multivariada, classificação contínua (fuzzy), geoestatística, métodos fractais, morfologia matemática e teoria do caos (Burrough et al., 1994). Embora esses métodos estatísticos permitam inferir sobre a variabilidade espacial do solo (vertical e horizontal), a dependência espacial entre as amostras somente pode ser modelada por meio da geoestatística (Webster, 2000). Análises estatísticas clássicas que consideram a independência entre as amostras, baseadas na média, vêm sendo substituídas por análises geoestatísticas fundamentadas na teoria das variáveis regionalizadas (Isaaks \& Srivastava, 1989), por intermédio do semivariograma e da dependência espacial.

As formas de paisagem estão relacionadas com a distribuição dos fluxos de água (divergência e convergência) no solo, com influência na drenagem, condicionando ambientes erosionais e deposicionais. Portanto, os estudos da posição do solo na paisagem têm esclarecido as modificações que ocorrem nos processos geomórficos, os quais influenciam diretamente na variabilidade espacial de atributos do solo. Assim, neste trabalho, objetivou-se caracterizar a variabilidade espacial da textura de um Latossolo Vermelho distrófico sob cultivo de citros.

\section{MATERIAL E MÉTODOS}

A área de estudo está localizada no município de Gavião Peixoto (SP), no Planalto Ocidental Paulista com coordenadas geográfica de $21^{\circ} 75^{\prime} \mathrm{S}$ e $48^{\circ} 46^{\prime} \mathrm{O}$, com altitude variando de 525 a 580 metros. O clima da região foi classificado pelo método de Köppen, como subtropical com inverno seco (Cwa), com precipitação média de 1.400 $\mathrm{mm}$, temperatura média anual de $21^{\circ} \mathrm{C}$, com temperatura no mês mais quente superior a $22{ }^{\circ} \mathrm{C}$ e a do mês mais frio inferior a $18^{\circ} \mathrm{C}$, e umidade relativa do ar de $70 \%$.

A geologia é representada por sedimentos do Grupo Bauru (Formações Adamantina). A porção mais elevada da região é caracterizada pela presença de topos, com encostas convexas de pouca inclinação (2 a 5\%). Essas encostas são interrompidas por ravinas, relativamente profundas, formando vales em " $v$ " aberto, de inclinações escalonadas desde o ombro até os sopés. O solo da área de estudo foi classificado como Latossolo Vermelho distrófico, A moderado, textura média a argilosa (Embrapa, 2006). A área em estudo encontra-se sob cultivo de laranja da variedade pera-rio (Citrus sinensis) por 14 anos.

A área de estudo encontra-se em uma encosta representativa da região, o experimento foi montado após identificação e delimitação das pedoformas (modelos de paisagem), com o auxílio de fotos aéreas e mapa de levantamento planialtimétrico (escala 1:10.000). Essa encosta foi dividida em três segmentos: topo, meia encosta e encosta inferior. Uma área suavemente côncava, ocupando o topo e parte da meia encosta foi delimitada (Figura 1). O restante da meia encosta é caracterizado por uma forma convexa e a encosta inferior por uma linear. A área côncava corresponde ao início de uma convergência para uma nascente (bacia de $1^{\mathrm{a}}$ ordem) situada a aproximadamente $400 \mathrm{~m}$ da área de estudo. Com a utilização de um aparelho de DGPS levantaram-se as cotas altimétricas e estabeleceu uma malha, com intervalos regulares de $50 \mathrm{~m}$, perfazendo um total de 333 pontos em uma área de 83,5 hectares.

$\mathrm{Na}$ intersecção dessa malha foi georreferenciada à planta de laranja mais próxima, e o solo foi amostrado na projeção da copa desta planta nas profundidades de $0,0-0,2$ $\mathrm{m}$ e $0,6-0,8 \mathrm{~m}$ nos meses de julho e agosto de 2003. Nestas amostras, foram analisados a composição granulométrica pelo método da pipeta, utilizando solução de $\mathrm{NaOH} 0,1 \mathrm{~N}$ como dispersante químico e agitação mecânica em aparato de baixa rotação por 16 horas, seguindo metodologia proposta pela Embrapa (1997), com modificações.

A fração argila foi separada por sedimentação, seguindo a Lei de Stokes, a fração areia por tamisação e a fração silte determinada por diferença. A fração areia, após secagem e pesagem, foi subdividida em cinco subfrações, areia muito grossa (AMG), areia grossa (AG), areia média (AM), areia fina $(\mathrm{AF})$ e areia muito fina (AMF), em peneiras de 2-1 mm; 1-0,5 $\mathrm{mm} ; 0,5-0,25 \mathrm{~mm} ; 0,25-0,10 \mathrm{~mm}$ e $0,10-0,05 \mathrm{~mm}$, respectivamente.

As frações granulométricas foram analisadas por meio da análise estatística descritiva calculando-se a média, mediana, coeficiente de variação, coeficiente de assimetria e coeficiente de curtose. A hipótese de normalidade dos dados foi testada pelo teste de Kolmogorov-Smirnov, por meio do programa computacional SAS (Schlotzhaver \& Littell, 1997).

A dependência espacial foi analisada por meio de ajustes de semivariogramas (Vieira, 2000), com base na pressuposição de estacionariedade da hipótese intrínseca. Os modelos dos semivariogramas foram ajustados por meio do programa GS ${ }^{+}$(versão 7.0) (Gamma Design Software, 2004) e, posteriormente, tais modelos foram usados no desenvolvimento de mapas de isolinhas (krigagem). Para elaboração dos mapas de distribuição espacial das frações foi utilizado o programa Surfer 8.0 (Golden Software, 1999). Para analisar o grau da dependência espacial das frações em estudo, utilizou-se a classificação de Cambardella et al. (1994), em que são considerados de dependência espacial forte os semivariogramas que têm um efeito pepita $<25 \%$ do patamar, moderada quando está entre 25 e $75 \%$, e fraca $>75 \%$. 


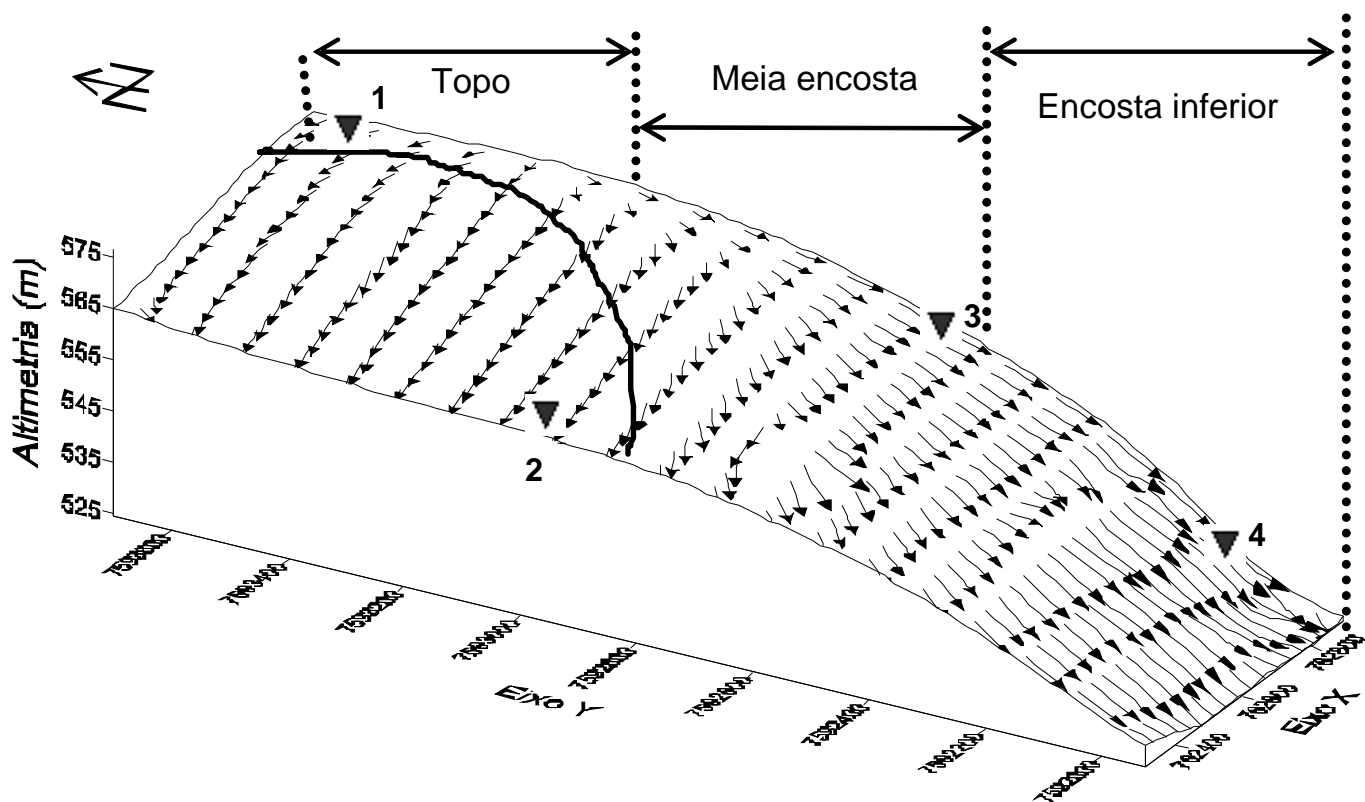

Figura 1 - Modelo de elevação digital mostrando os segmentos da encosta, os locais de amostragem dos pedons ( $\boldsymbol{\nabla}$ ), e vetores representando o caminhamento superficial (setas) e intensidade (tamanho da seta) dos fluxos de água. No topo e parte da meia encosta está indicada a área suavemente côncava.

\section{RESULTADOS E DISCUSSÃO}

Os resultados da análise estatística descritiva encontram-se na Tabela 1. Na análise granulométrica não foi detectada a fração areia muito grossa, provavelmente decorrente de os Latossolos da região serem formados a partir dos sedimentos da formação Adamantina, onde predominam a presença de bancos de arenitos de granulação fina a muito fina (Ibrahim, 2002). Observa-se que todas as variáveis apresentaram distribuições simétricas nas duas profundidades, exceto AF na profundidade de $0,0-0,2 \mathrm{~m}$ e argila na profundidade de 0,6-0,8 m, as quais apresentam problemas nas caldas. Segundo Isaaks \& Srivastava (1989), o coeficiente de assimetria e curtose é mais sensível a valores extremos do que a média e o desvio padrão, uma vez que um único valor pode influenciar fortemente estes coeficientes, pois os desvios entre cada valor e a média são elevados à terceira potência.

Apesar do teste de normalidade mostrar distribuição normal apenas para a variável AMF, nas duas profundidades, os valores da média e mediana de todos os atributos granulométricos estudados são próximos, mostrando que os dados não apresentam assimetria acentuada e, segundo Little \& Hills (1978), quando os valores da média, mediana e moda apresentam valores semelhantes, os dados apresentam ou aproximam da distribuição normal. Isso pode ser um indicativo de que as medidas de tendência central não são dominadas por valores atípicos na distribuição (Cambardella et al., 1994), demonstrando que todos os atributos envolvidos no estudo estão aproximando-se de uma distribuição normal indicando que os dados estão adequados para o uso da geoestatística.

De acordo com a classificação do coeficiente de variação (CV), proposta por Warrick \& Nielsen (1980), a argila e AT nas profundidades de 0,0-0,2 m e 0,6-0,8 m apresentaram baixo CV $(<12 \%)$ (Tabela 1$)$. A AM e AF apresentaram CV médio (12 a 24\%) nas profundidades de $0,0-0,2 \mathrm{~m}$ e $0,6-0,8 \mathrm{~m}$ e para o silte, areia grossa e areia muito fina foi observado $\mathrm{CV}$ alto (> 24\%) nas duas profundidades estudadas.

Os resultados da análise geoestatística mostraram que todos os atributos granulométricos apresentaram dependência espacial nas duas profundidades estudadas (Tabela 2 e Figuras 2 e 3). A análise dos semivariogramas para os atributos granulométricos em estudo, não indicou nenhuma direção preferencial, ou seja, os semivariogramas não indicaram presença de anisotropia, a variabilidade espacial dos dados ocorre com um mesmo padrão em todas as direções (Vieira, 2000). 
LEÃO, M. G. A. et al.

Tabela 1 - Medidas descritivas dos atributos argila, silte, areia total (AT), areia grossa (AG), areia média (AM), areia fina $(\mathrm{AF})$ e areia muito fina (AMF) do solo nas profundidades de 0,0-0,2 $\mathrm{m}$ e 0,6-0,8 $\mathrm{m}$.

\begin{tabular}{lcccccc}
\hline Atributos Granulométricos & Média & Mediana & Assimetria & Curtose & ${ }^{1} \mathrm{CV}$ & ${ }^{2} \mathrm{~d}$ \\
\hline & \multicolumn{7}{c}{$0,0-0,2 \mathrm{~m}$} \\
Argila $\left(\mathrm{g} \mathrm{kg}^{-1}\right)$ & 253 & 251 & 0,28 & 0,52 & 10,07 & 0,19 \\
Areia total $\left(\mathrm{g} \mathrm{kg}^{-1}\right)$ & 700 & 702 & $-0,43$ & 0,52 & 5,04 & 0,17 \\
Silte $\left(\mathrm{g} \mathrm{kg}^{-1}\right)$ & 47 & 47 & 0,36 & 0,21 & 42,46 & 0,18 \\
Areia grossa $\left(\mathrm{g} \mathrm{kg}^{-1}\right)$ & 60 & 56 & 0,68 & 0,54 & 31,74 & 0,19 \\
Areia média $\left(\mathrm{g} \mathrm{kg}^{-1}\right)$ & 229 & 214 & 0,94 & 0,34 & 19,68 & 0,21 \\
Areia fina $\left(\mathrm{g} \mathrm{kg}^{-1}\right)$ & 346 & 355 & $-1,05$ & 1,49 & 14,76 & 0,24 \\
Areia muito fina $\left(\mathrm{g} \mathrm{kg}^{-1}\right)$ & 65 & 66 & $-0,04$ & 0,75 & 30,76 & $0,12^{\mathrm{ns}}$ \\
& & \multicolumn{7}{c}{$0,6-0,8 \mathrm{~m}$} & & 0,23 \\
Argila $\left(\mathrm{g} \mathrm{kg}^{-1}\right)$ & 302 & 300 & $-0,82$ & 1,77 & 9,74 & 0,18 \\
Areia total $\left(\mathrm{g} \mathrm{kg}^{-1}\right)$ & 667 & 672 & $-0,68$ & 0,42 & 4,31 & 0,19 \\
Silte $\left(\mathrm{g} \mathrm{kg}^{-1}\right)$ & 31 & 28 & 0,43 & 0,90 & 44,61 & 0,17 \\
Areia grossa $\left(\mathrm{g} \mathrm{kg}^{-1}\right)$ & 54 & 50 & 0,78 & 0,46 & 30,77 & 0,20 \\
Areia média $\left(\mathrm{g} \mathrm{kg}^{-1}\right)$ & 198 & 193 & 0,91 & 0,75 & 20,29 & 0,19 \\
Areia fina $\left(\mathrm{g} \mathrm{kg}^{-1}\right)$ & 340 & 345 & $-0,98$ & 0,81 & 13,45 & $0,11^{\mathrm{ns}}$ \\
Areia muito fina $\left(\mathrm{g} \mathrm{kg}^{-1}\right)$ & 75 & 72 & 0,12 & $-0,31$ & 26,69 & \\
\hline
\end{tabular}

${ }^{1} \mathrm{CV}=$ coeficiente de variação; ${ }^{2} \mathrm{~d}=$ estatística do teste de Kolmogorov-Smirnov, não significativo a $5 \%$ de probabilidade (ns).

Tabela 2 - Descrição dos modelos de semivariogramas para os atributos argila, silte, areia total (AT), areia grossa (AG), areia média (AM), areia fina (AF) e areia muito fina (AMF) do solo nas profundidades de 0,0-0,2 m e 0,6-0,8 m.

\begin{tabular}{|c|c|c|c|c|c|c|c|}
\hline \multirow[b]{2}{*}{$\begin{array}{c}\text { Atributos } \\
\text { Granulométricos }\end{array}$} & \multicolumn{7}{|c|}{ Parâmetros } \\
\hline & Modelo & ${ }^{1} \mathrm{C}_{0}$ & patamar & alcance & ${ }^{2} \mathrm{C}_{0} /\left(\mathrm{C}_{0}+\mathrm{C}_{1}\right)$ & ${ }^{3} \mathrm{R}^{2}$ & ${ }^{4} \mathrm{SQR}$ \\
\hline \multicolumn{8}{|c|}{$0,0-0,2 \mathrm{~m}$} \\
\hline Argila $\left(\mathrm{g} \mathrm{kg}^{-1}\right)$ & Esférico & 127 & 680 & 310 & 19 & 94 & 27568 \\
\hline $\operatorname{AT}\left(\mathrm{g} \mathrm{kg}^{-1}\right)$ & Esférico & 307 & 1215 & 378 & 25 & 97 & 28635 \\
\hline Silte $\left(\mathrm{g} \mathrm{kg}^{-1}\right)$ & Esférico & 86 & 255 & 365 & 34 & 90 & 3842 \\
\hline $\mathrm{AG}\left(\mathrm{g} \mathrm{kg}^{-1}\right)$ & Exponencial & 57 & 366 & 603 & 16 & 98 & 1064 \\
\hline $\mathrm{AM}\left(\mathrm{g} \mathrm{kg}^{-1}\right)$ & Esférico & 108 & 2218 & 508 & 5 & 99 & 46694 \\
\hline $\mathrm{AF}\left(\mathrm{g} \mathrm{kg}^{-1}\right)$ & Esférico & 197 & 2858 & 585 & 7 & 99 & 44156 \\
\hline $\mathrm{AMF}\left(\mathrm{g} \mathrm{kg}^{-1}\right)$ & Esférico & 187 & 442 & 474 & 42 & 97 & 2733 \\
\hline \multicolumn{8}{|c|}{$0,6-0,8 \mathrm{~m}$} \\
\hline Argila $\left(\mathrm{g} \mathrm{kg}^{-1}\right)$ & Esférico & 357 & 809 & 371 & 44 & 98 & 3033 \\
\hline $\mathrm{AT}\left(\mathrm{g} \mathrm{kg}^{-1}\right)$ & Esférico & 289 & 813 & 395 & 36 & 98 & 6005 \\
\hline Silte $\left(\mathrm{g} \mathrm{kg}^{-1}\right)$ & Esférico & 43 & 170 & 482 & 26 & 98 & 132 \\
\hline $\mathrm{AG}\left(\mathrm{g} \mathrm{kg}^{-1}\right)$ & Exponencial & 37 & 266 & 668 & 14 & 98 & 509 \\
\hline $\mathrm{AM}\left(\mathrm{g} \mathrm{kg}^{-1}\right)$ & Esférico & 153 & 1842 & 506 & 8 & 98 & 59437 \\
\hline $\mathrm{AF}\left(\mathrm{g} \mathrm{kg}^{-1}\right)$ & Esférico & 26 & 1623 & 511 & 2 & 99 & 9286 \\
\hline $\operatorname{AMF}\left(\mathrm{g} \mathrm{kg}^{-1}\right)$ & Esférico & 23 & 380 & 426 & 6 & 96 & 7796 \\
\hline
\end{tabular}

${ }^{1} \mathrm{C}_{0}=$ efeito pepita; ${ }^{2} \mathrm{C}_{0} /\left(\mathrm{C}_{0}+\mathrm{C}_{1}\right)=$ grau de dependência espacial; ${ }^{3} \mathrm{R}^{2}=$ coeficiente de determinação; ${ }^{4} \mathrm{SQR}=$ soma dos quadrados dos resíduos. 


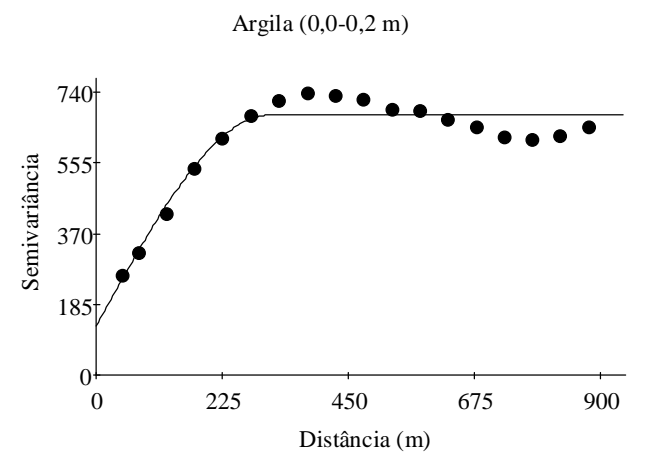

Esf (127-680-310)

Silte $(0,0-0,2 \mathrm{~m})$

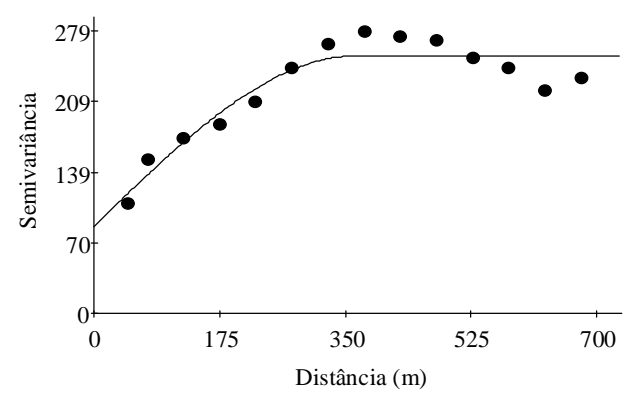

Esf (86-255-365)

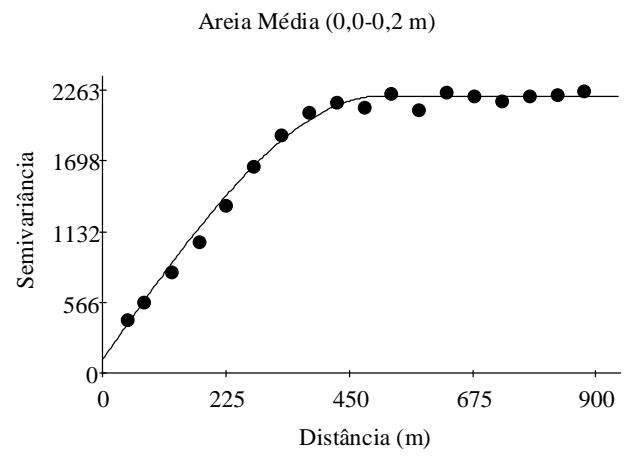

Esf (108-2218-508)

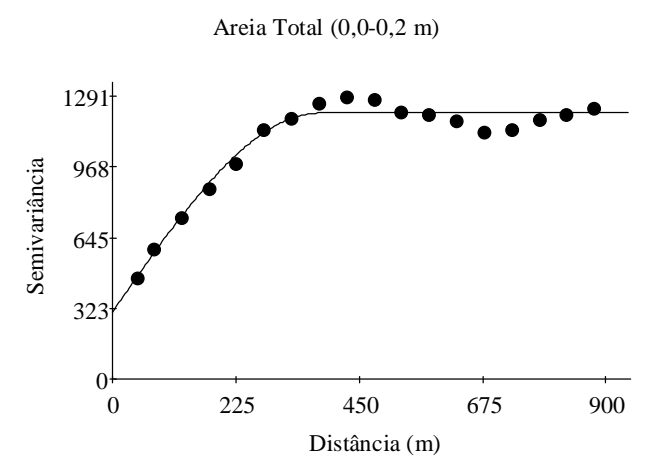

Esf (307-1215-378)

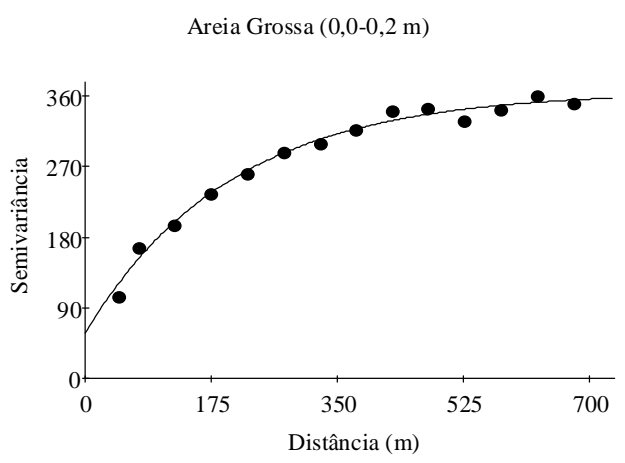

Exp (57-366-603)

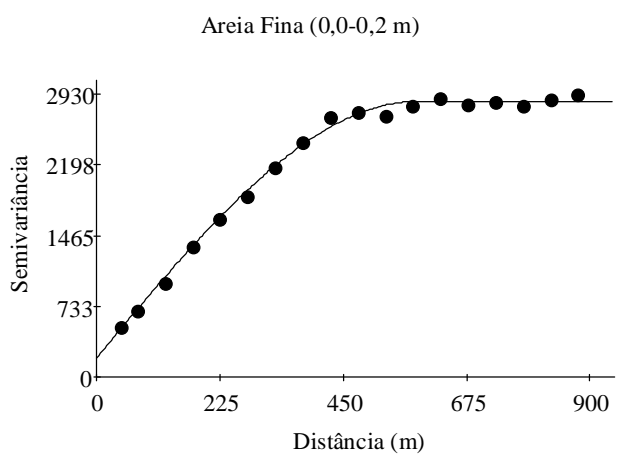

Esf (197-2858-585)

Figura 2 - Semivariogramas dos atributos granulométricos do solo em área cultivada com citros, na profundidade de 0,0-0,2 m.

O efeito pepita é a variabilidade ao acaso ou não detectada pela escala de amostragem (Cambardella et al., 1994). A relação entre o efeito pepita e o patamar do semivariograma indica o grau de dependência espacial do atributo (Trangmar et al., 1985). Pela análise da relação $C_{0} /$
$\left(\mathrm{C}_{0}+\mathrm{C}_{1}\right)$ as variáveis granulométricas silte e $\mathrm{AMF}$ na profundidade de 0,0-0,2 $\mathrm{m}$ e argila, AT e silte na profundidade de 0,6-0,8 $\mathrm{m}$ apresentaram dependência espacial moderada e as demais variáveis apresentaram forte dependência espacial nas profundidades estudadas. 
Silte $(0,6-0,8 \mathrm{~m})$

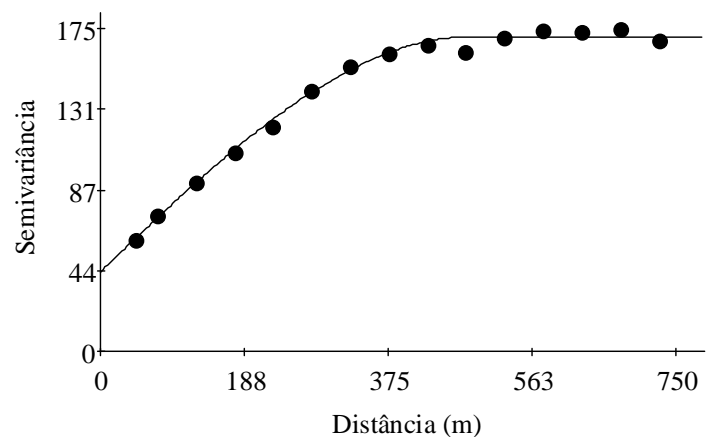

Esf (43-170-482)

Areia Média (0,6-0,8 m)

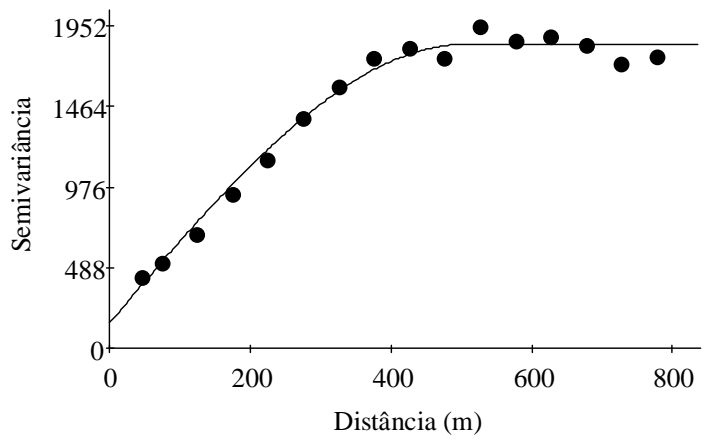

Esf (153-1842-506)
Areia Grossa (0,6-0,8 m)

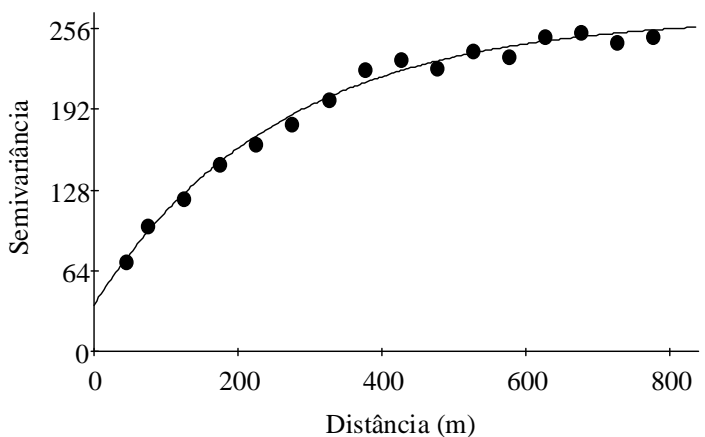

Exp (37-266-668)

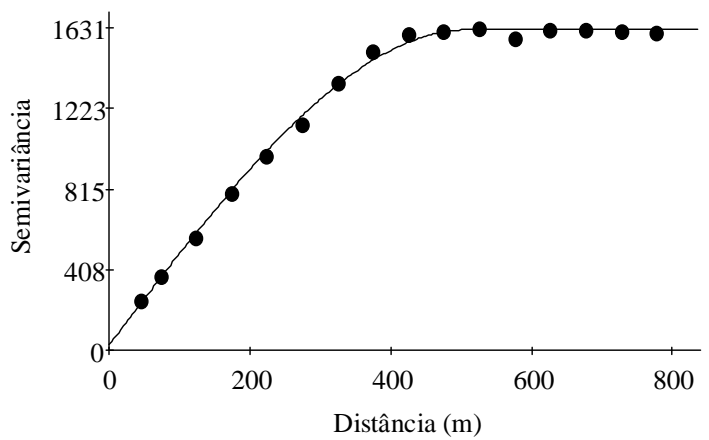

Esf (26-1623-511)

Figura 3 - Semivariogramas dos atributos granulométricos do solo em área cultivada com citros, na profundidade de $0,6-0,8 \mathrm{~m}$.

Os atributos granulométricos apresentaram diferentes alcances, na profundidade de 0,0-0,2 m, entre 310 a $603 \mathrm{~m}$ e 371 a $668 \mathrm{~m}$ na profundidade de $0,6-0,8 \mathrm{~m}$ (Tabela 2). $\mathrm{O}$ alcance menor na profundidade $0,0-0,2 \mathrm{~m}$ pode indicar um possível efeito do manejo da cultura. Souza et al. (2003) obtiveram um alcance de $561 \mathrm{~m}$ para argila em uma superfície côncava e para silte alcances de $205 \mathrm{~m}$ para este mesmo tipo de superfície e $370 \mathrm{~m}$ em uma superfície linear. Souza et al. (2004b) em uma área de 42 ha, sob cultivo de cana-de-açúcar, obtiveram alcances entre 200 e $367 \mathrm{~m}$ na camada de $0,0-0,2$ m e de 58 a 215 m na camada de $0,6-0,8$ $\mathrm{m}$ para os atributos granulométricos. Observa-se que os valores de alcance obtidos por Souza et al. (2003, 2004b) foi menor, o que está relacionado à escala de amostragem dos estudos. Trangmar et al. (1985) afirma que o alcance depende do tamanho da área amostrada e da escala de observação, sendo tanto maior o alcance quanto maior for o intervalo entre medidas.

Os parâmetros dos modelos de semivariogramas ajustados foram utilizados para estimar valores em locais não amostrados por meio da krigagem. Nas Figuras 4 e 5 apresentam-se os mapas de krigagem (isolinhas) dos atributos granulométricos. Verifica-se que a distribuição superficial da argila registra seus maiores teores nas posições de topo e na parte leste da encosta (próximo ao espigão) da posição de meia encosta. Na posição de meia encosta para ambas as profundidades observam-se os menores teores de silte, corroborando com os menores teores de argila e maiores de areia. Isso indica uma área de maior suscetibilidade, remoção seletiva de partículas pelo caminhamento de água, essa área esta inclusa na área suavemente côncava. Isso demonstra que a variabilidade 
da textura do solo esta relacionada aos fluxos de água. O relevo, mesmo que em pequena escala de variação de suas formas, condiciona o caminhamento superficial e subsuperficial da água, assim pode-se inferir que a topografia influencia na distribuição espacial da textura.

$\mathrm{Na}$ camada superficial, o teor de argila varia de 200 a $280 \mathrm{~g} \mathrm{~kg}^{-1}$, enquadrando-se no grupamento de textura média (Figura 4). Na camada subsuperficial, os teores médios de argila são relativamente superiores, ainda se enquadrando no grupamento da textura média, porém, limítrofe para textura argilosa, segundo Embrapa (2006) (Figura 5). Observa-se um aumento relativo nos teores de argila em profundidade, porém, não suficiente para caracterizar um horizonte B textural. Segundo Ibrahim (2002), é comum encontrar em solos originados do sedimento do Grupo Bauru a associação de Latossolos com Argissolos, concordando com os resultados obtidos por Vidal-Torrado \& Lepsch (1993) e Marques Júnior \& Lepsch (2000).

Para o atributo silte (Figuras 4 e 5), nota-se semelhança entre os padrão de distribuição espacial, em ambas as profundidades, porém, na superfície este padrão é, relativamente, mais homogêneo tornando possível afirmar que os valores mais baixos e medianos se encontram no topo e meia encosta, enquanto que os valores maiores estão no final da encosta inferior. Em subsuperfície, os menores valores para esse atributo encontram no topo, valores medianos a altos na meia encosta e os medianos na encosta inferior. A distribuição espacial dos valores da AT (Figuras 4 e 5) em toda a vertente apresenta-se muito semelhante aos valores opostos da distribuição de porcentagem de argila, tanto na camada superficial como subsuperficial.

Os mapas de AG (Figuras 4 e 5) informam que nas duas camadas há um padrão de distribuição onde os maiores valores se encontram concentrados do lado oeste no topo da encosta, nessa área há também a maior variabilidade de dados. A leste do topo, os valores são medianos com uma contribuição de valores baixos, diferindo muito pouco, dos valores encontrados na meia encosta e na encosta inferior, onde predominam os valores baixos. $\mathrm{Na}$ área ligeiramente côncava, o mapa superficial de AG é semelhante ao mapa de AT, assim sendo, no topo a maior contribuição das frações de areia é da AG. Para a AM, pode-se observar que a distribuição é semelhante a AG.

Para os mapas de AF (Figuras 4 e 5) a distribuição espacial superficial apresenta os menores valores no topo, na meia encosta, apresenta uma faixa com os maiores valores desse atributo, e na encosta inferior os valores são medianos. Observa-se a semelhança entre os padrões de distribuição espacial dos atributos AT e AF na meia encosta e encosta inferior, assim é possível inferir que para o atributo AT, nesses segmentos, a maior contribuição é da AF. As distribuições espaciais da AMF nas duas profundidades são muito semelhantes, e seus maiores valores também ocorrem no topo. Os mapas de AF e AMF são semelhantes nesse segmento. $\mathrm{O}$ atributo AMF apresenta valores medianos na meia encosta e os menores na encosta inferior.

Observando os mapas das Figuras 4 e 5, nota-se que a distribuição espacial dos atributos, em ambas as profundidades, apresenta uma dependência da direção e intensidade dos fluxos de água tal como simulados na Figura 1. O comportamento destes fluxos de água obedece às variações das formas de relevo. Assim, na posição de topo, a forma côncava condiciona o movimento das partículas na direção perpendicular ao sentido da vertente, indicado pelas isolinhas. No segmento convexo da meia encosta (forma convexa) e encosta inferior (forma linear) visualiza-se a inversão dos movimentos na direção paralela ao sentido da vertente. Ao avaliarem a textura em transeções, Miller et al. (1988), concluíram que esses atributos são afetados pela posição que o solo se encontra na paisagem, que possuem dependência espacial definida e que tanto o manejo como erosão hídrica contribui para essa distribuição espacial.

No presente estudo, o comportamento da argila na camada superficial e subsuperficial, obedece ao fluxo de água, e este é dependente do relevo. Essa evidência corrobora com a pressuposição de homogeneidade da distribuição de argila em profundidade nos latossolos (Embrapa, 2006). Esse comportamento do atributo diagnóstico argila é um indicador de comportamento similar de outros atributos diagnósticos e acessórios que podem interferir na variabilidade da produção e qualidade do fruto da laranja.

Trabalhando com um Latossolo, Souza et al. (2003) verificaram que a maior variabilidade espacial para os atributos granulométricos ocorreu na pedoforma côncava, corroborando com os dados deste trabalho. Ao estudarem os atributos físicos em um segmento com pedoforma linear e segmento com pedoformas côncavas e convexas, Souza et al. (2004a), encontraram a maior variabilidade desses atributos nas formas com curvatura côncavas e convexas. Esses dados corroboram com a necessidade de se associar pedoformas aos mapas de variabilidade nessa escala de estudos, para melhor entendimento da área e possibilitar a transferência de conhecimento para áreas semelhantes. 

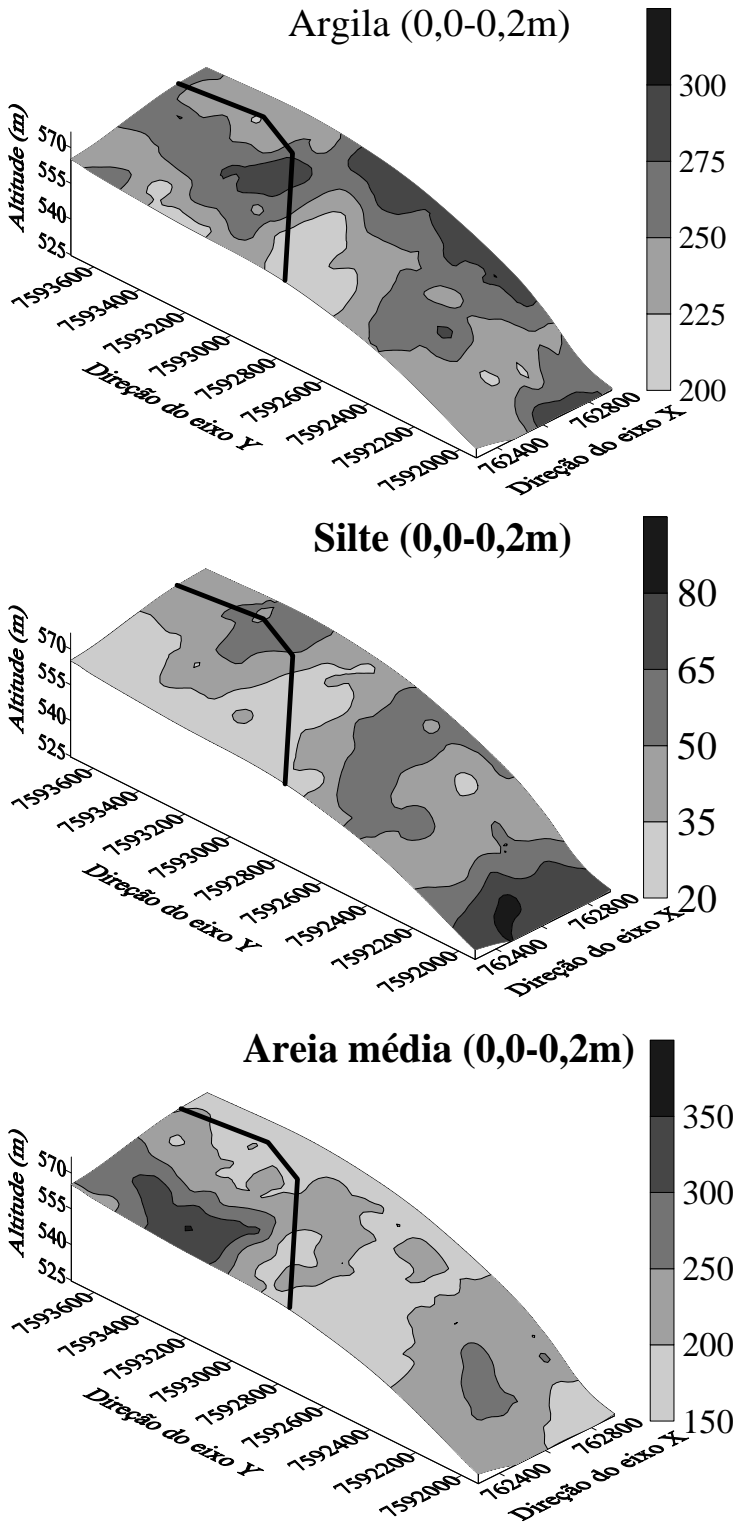

Figura 4 - Mapas de krigagem dos atributos granulométricos em área cultivada com citros, na profundidade de 0,0-0,2 m.

Ciênc. agrotec., Lavras, v. 34, n. 1, p. 121-131, jan./fev., 2010
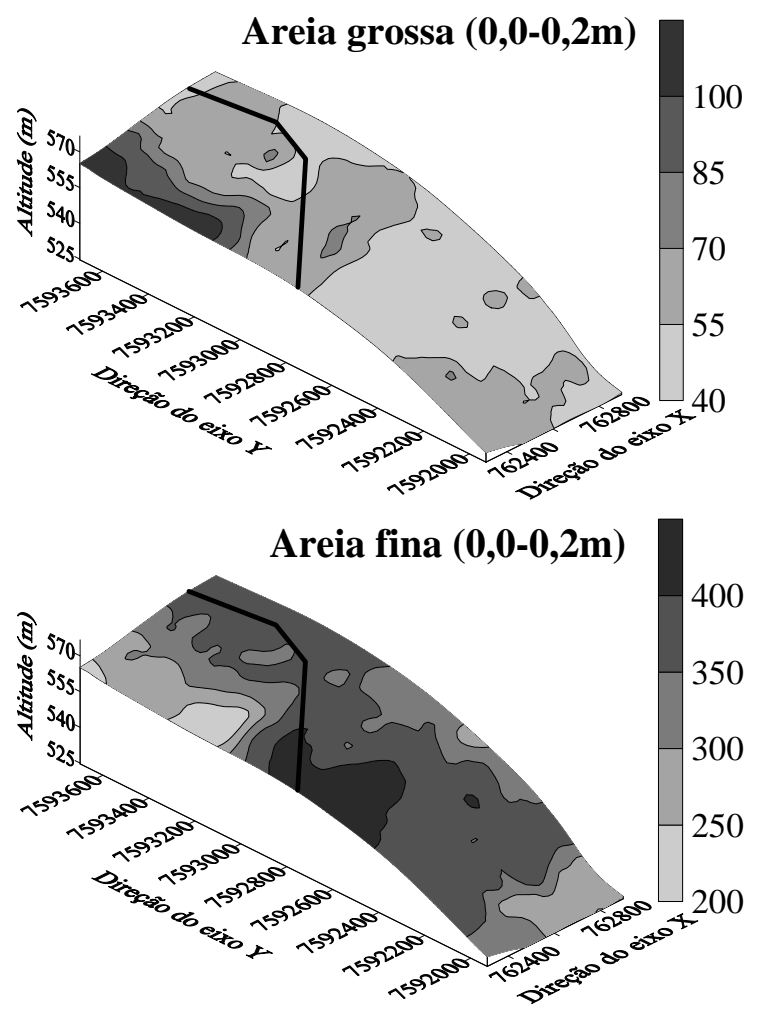

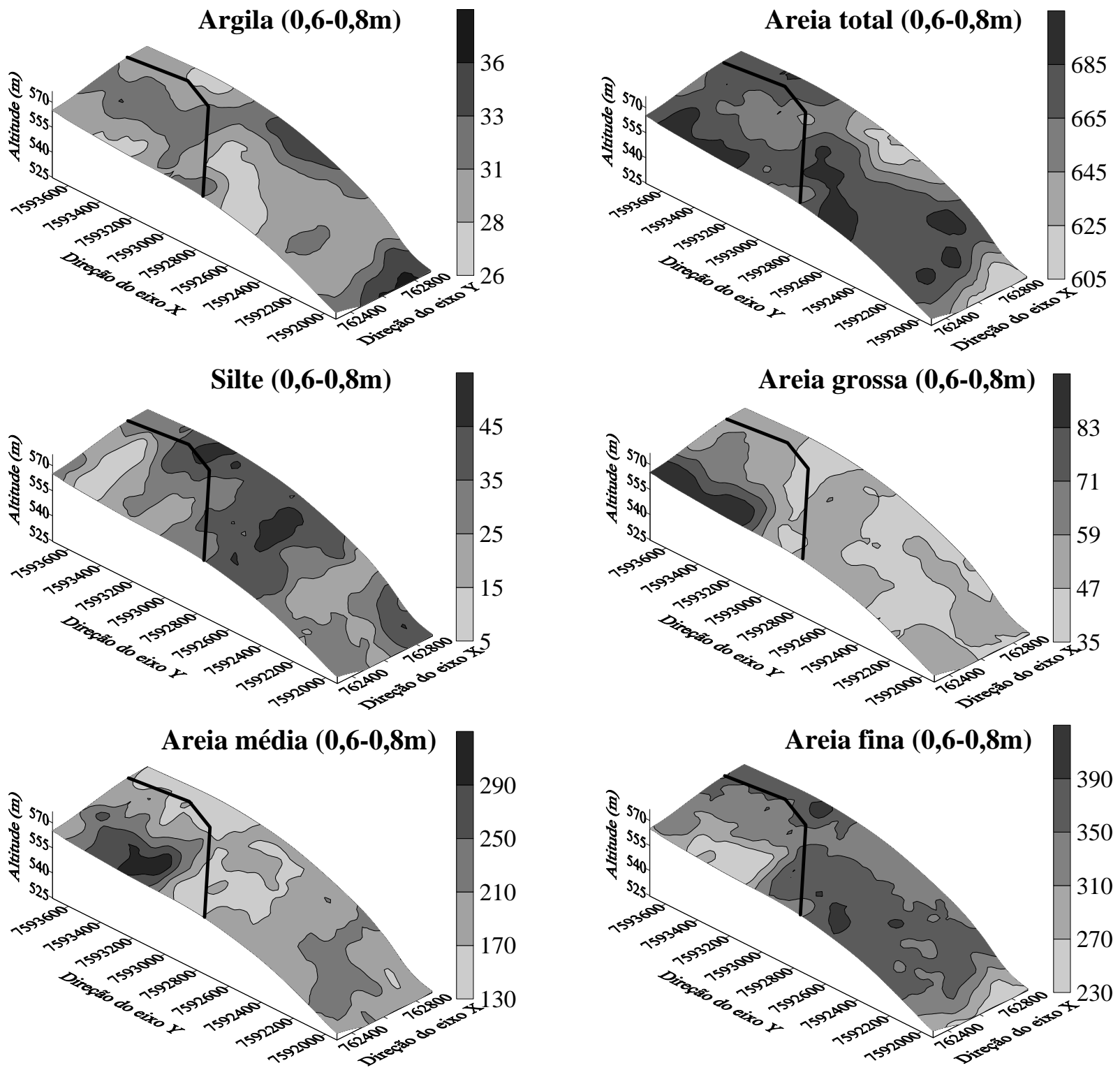

Figura 5 - Mapas de krigagem dos atributos granulométricos em área cultivada com citros, na profundidade de 0,6-0,8 m. 


\section{CONCLUSÕES}

O comportamento espacial da granulometria de latossolos está diretamente relacionado com as formas do relevo neste estudo, que controla o sentido dos fluxos de água superficial e subsuperficial.

O conceito de homogeneidade da distribuição de argila no perfil dos latossolos é uma informação que pode ser ajustada pelo conhecimento do padrão espacial dessa distribuição em diferentes formas do relevo.

\section{REFERÊNCIAS BIBLIOGRÁFICAS}

BOUMA, J.; STOORVOGEL, J.; ALPHEN, B.J. van; BOOLTINK, H.W.G. Pedology, precision agriculture, and the changing paradigm of agricultural research. Soil Science Society of America Journal, Madison, v.63, n.6, p.1763-1768, 1999.

BURROUGH, P.A.; BOUMA, J.; YATES, S.R. The state of the art in pedometrics. Geoderma, Amsterdam, v.62, n.1/3, p.311-326, 1994.

CAMBARDELLA, C.A.; MOORMAN, T.B.; NOVAK, J.M.; PARKIN, T.B.; KARLEN, D.L.; TURCO, R.F.; KONOPKA, A.E. Field scale variability of soil properties in Central Iowa soils. Soil Science Society of America Journal, Madison, v.58, n.5, p.1501-1511, 1994.

DANIELS, R.B.; NELSON, L.A. Soil variability and productivity: Future developments. In: BOERSMA, L.L. Future developments in soil science research. Soil Science Society of America Journal, Madison, v.51, n.2, p.279-291, 1987.

\section{EMPRESA BRASILEIRA DE PESQUISA}

AGROPECUÁRIA. Manual de métodos de análise de solo. 2.ed. Rio de Janeiro: Ministério da Agricultura e do Abastecimento, 1997. 212p.

\section{EMPRESA BRASILEIRA DE PESQUISA}

AGROPECUÁRIA. Centro Nacional de Pesquisa de Solos. Sistema Brasileiro de Classificação de Solos. Rio de Janeiro, 2006. 306p.

GAMMA DESIGN SOFTWARE. Geoestatistics for the environmental sciences. Version 7.0. Michigan, 2004. 1 CD-ROM.

GOBIN, A.; CAMPLING, P.; FEYEN, J. Soil-landscape modelling to quantify spatial variability of soil texture.
Physics and Chemistry of the Earth, Amsterdam, v.26, n.1, p.41-45, 2001.

GOLDEN SOFTWARE INC. Surfer for windows: realese 7.0, contouring and 3D surface mapping for scientist's engineer's user's guide. New York, 1999. 619p.

IBRAHIM, L. Caracterização física, química e mineralógica e morfológica de uma sequiência de solos em Lins (SP). 2002. 84f. Dissertação (Mestrado em Ciência do Solo e Nutrição de Plantas)-Escola Superior de Agricultura "Luiz de Queiroz", Universidade de São Paulo, Piracicaba, 2002.

ISAAKS, E.H.; SRIVASTAVA, R.M. An introduction to applied geoestatistics. New York: Oxford University, 1989. 561p.

LITTLE, T.M.; HILLS, F.J. Agricultural experimentation. New York: J.Wiley, 1978. 350p.

MARQUES JÚNIOR, J.; LEPSCH, I.F. Depósitos superficiais neocenozóicos, superfícies geomórficas e solos em Monte Alto, SP. Geociência, São Paulo, v.19, n.2, p.265-281, 2000 .

MILLER, M.P.; SINGER, M.J.; NIELSEN, D.R. Spatial variability of wheat yield and soil proprieties on complex hills. Soil Science Society of America Journal, Madison, v.52, n.4, p.1133-1141, 1988.

SCHLOTZHAVER, S.D.; LITTELL, R.C. SAS: system for elementary statistical analysis. 2.ed. Cory: SAS Institute, 1997. 905p.

SOUZA, C.K.; MARQUES JÚNIOR, J.; MARTINS FILHO, M.V.; PEREIRA, G.T. Influência do relevo na variação anisotrópica dos atributos químicos e granulométricos de um Latossolo em Jaboticabal-SP. Engenharia Agrícola, Jaboticabal, v.23, n.3, p.486-495, 2003.

SOUZA, Z.M.; MARQUES JÚNIOR, J.; PEREIRA, G.T. Variabilidade espacial de atributos físicos do solo em diferentes formas do relevo sob cultivo de cana-deaçúcar. Revista Brasileira de Ciência do Solo, Viçosa, v.28, n.6, p.937-944, 2004a.

SOUZA, Z.M.; MARQUES JÚNIOR, J.; PEREIRA, G.T.; BARBIERI, D.M. Variabilidade espacial da textura de um Latossolo Vermelho eutroférrico sob cultivo de cana-deaçúcar. Engenharia Agrícola, Jaboticabal, v.24, n.2, p.309-319, 2004b. 
TRANGMAR, B.B.; YOST, R.S.; UEHARA, G. Application of geostatistics to spatial studies of soil properties. Advances in Agronomy, New York, v.38, n.1, p.54-94, 1985.

VIDAL-TORRADO, P.; LEPSCH, I.F. Morfogênese dos solos de uma topossequência com transição B latossólico x B textural sobre migmatitos em Mococa (SP). Revista Brasileira de Ciência do Solo, Campinas, v.17, n.1, p.109-119, 1993.

VIEIRA, S.R. Geoestatística em estudos de variabilidade espacial do solo. In: NOVAIS, R.F.; ALVAREZ, V.H.; SCHAEFER, C.E.G.R. (Eds.). Tópicos em ciência do solo. Viçosa: Sociedade Brasileira de Ciência do Solo, 2000. v.1, p.1-53.

WARRICK, A.W.; NIELSEN, D.R. Spatial variability of soil physical properties in the field. In: HILLEL, D. (Ed.). Applications of soil physics. New York: Academic, 1980. chap.2, p.319-344.
WEBSTER, R. Is soil variation random? Geoderma, Amsterdam, v.97, n.1/2, p.149-163, 2000.

WEBSTER, R.; BUTLER, B.E. Soil classification and survey studies at Ginninderra. Australia Journal of Soil Research, Collingwood, v.14, n.1, p.1-24, 1976.

WILDING, L.P.; DREES, L.R. Spatial variability and pedology. In: WILDING, L.P. Pedogenesis and soil taxonomy: I concepts and interactions. New York: Elsevier, 1983. p.83-116.

WYSOCKI, D.A.; SCHOENEBERGER, P.J.

Geomorphology of soil landscapes. In: SUMMER M.E. (Ed.). London: Handbook of soil Science, 1999. p.5-38.

YOUNG, F.J.; HAMMER, R.D.; LARSEN D.

Frequency distribution of soil properties on a loessmantled Missouri watershed. Soil Science Society American Journal, Madison, v.63, n.2, p.178-185, 1999. 